\title{
Palliative care for people with COPD: we need to meet the challenge
}

\author{
Scott A. Murray, Hilary Pinnock*, Aziz Sheikh
}

Division of Community Health Sciences: GP Section, University of Edinburgh, 20, West Richmond St, Edinburgh, EH8 9DX, UK

Received 3 May 2006; accepted 20 August 2006

$$
\begin{aligned}
& \text { KEYWORDS } \\
& \text { COPD; } \\
& \text { Palliative care; } \\
& \text { Disease register }
\end{aligned}
$$

\begin{abstract}
Summary The need to extend the palliative care approach to people dying with a wide range of chronic diseases is increasingly recogniced. Whils of relevance internationally, this topic is particularly timely in tho UK os the ceneral Medical Services contract will reward practices thatrectes a resister of patients "in need of palliative/supportive care',-Dini_ulty piedicting prognosis can lead to uncertainty about which phtiens vinCOPJ to include in a egister, potentially reducing the impaci e: this Initiative. In this Discas: ior paper we highlight this challenge, and If er some practical stra'-Egies to help clinicians recognise these patients.

(c) 2006 Generd Piactice Ailways Group. Published by Elsevier Ltd. All rights resered
\end{abstract}

\section{Introduction}

The palliative care approach is increasingly being advocated for a broad range of chronic diseases [1]. Cancer now only accounts for about a quarter of deaths from progressive disease [2]. From April 2006, the General Medical Services contract governing UK general practice rewards practices that create a register of patients in need of supportive and palliative care [3]. A focus on people dying with advanced non-malignant disease such as chronic obstructive pulmonary disease (COPD) is welcome, but uncertainty about which patients with COPD to target may reduce the impact of this

\footnotetext{
* Corresponding author. Tel.: +44 (0) 131650 8102; fax: +44 (0) 1316509119.

E-mail address: hilary.pinnock@ed.ac.uk (H. Pinnock).
}

initiative [4]. In this Discussion paper we offer some pointers to help clinicians identify patients with COPD who might benefit from a holistic, patientcentred palliative approach.

\section{Why include patients with COPD on a supportive and palliative care register?}

Patients with severe COPD have multiple, extensive and prolonged needs. They may describe disabling shortness of breath, depression, cough, fatigue, pain, confusion, anorexia, or thirst [5-8]. This morbidity is reflected in severe impairment of quality of life and activities of daily living [5,6,9]. Social isolation is common [5]. Exacerbations may result in frequent hospital admissions and high use of primary care services $[5,9]$. The burden on carers 
is high, but less than half have access to appropriate social and nursing support [5-7,9]. Unmet spiritual distress increases anxiety, panic attacks and the unscheduled use of medical services [10].

There is a stark contrast between the experiences and services available for people with advanced cancer and COPD [11]. In the last year of life patients with COPD have worse quality of life, greater limitation of activity, and more anxiety and depression than patients with lung cancer, yet few receive specialist palliative care services [9]. Although over $80 \%$ are housebound and a third are chair-bound, less than half have mobility aids that might reduce social isolation. Information needs are rarely adequately met and few people with end-stage COPD are offered an opportunity to discuss prognosis and to make decisions about their end-of-life care [9]. The majority die in hospital [7] despite the recognition that many people would prefer to die at home.

Formally recognising these patients offers an opportunity to integrate active management with a palliative approach. Palliative care aims to improve the quality of life of patients and their families when facing life-threatening illness, through the prevention and relief of suffering by means of early identification and impeccable assessment and treatment of pain and other physical, psychospciat and spiritual problems [12]. Such an anpoaet may proceed in parallel with artive inandgement over many months or Vears, ensuring that patients wishes for symp comatic care aritio life support, care at home, or hospitalisation, are respected. Our aim should be to enable people with advanced COPD to achieve the good quality of life and death which we expect to achieve for those with cancer.

\section{Knowing who to put on the register}

Recognising when to include someone with COPD on a supportive and palliative care register is a major challenge. COPD illustrates the 'organ failure' end-of-life trajectory in which a gradual decline is punctuated by acute, potentially severe, exacerbations, any one of which may be fatal $[4,13]$. Death may appear to occur suddenly, before the patient is perceived as being "terminal", so missing the opportunity to address important issues.

This uncertain prognosis, compounded by a tendency of doctors who are familiar with patients to over-estimate survival [14], may make it difficult for clinicians to initiate discussions about end-oflife care planning - a situation that has been
Box 1: Possible ways of identifying patients with COPD for inclusion on a practice palliative care register

- Hospital admission for a severe exacerbation of COPD

- Being housebound due to COPD

- Having an $\mathrm{FEV}_{1}$ of $30 \%$ or less

- On long-term oxygen therapy

- Depression, poor quality of life.

- Other parameters such as low BMI and co-morbidities (especially heart failure)

- GPs and nurses asking themselves the question "Would I be surprised if my patient were to die in the next twelve months?" This could be considered during routine consultations or on reviewing the register. If the answer is "no" the palliative/anticipatory care approach may be indicated.

described as "prognostic paralysis" [4]. Active case finding (some suggested strategies are listed in Box 1) of patients who might benefit from a palliative care approach could prevent this. For

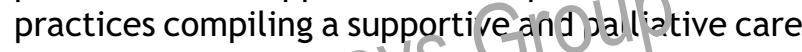
register for the firsplime, a practical starting point (n-1) be the systernatic flagging of hospital adrmissions for a severe exacerbation of COPD: only two th iicl: c) these patients survive two years $[15,6]$

Even when a poor prognosis is recognised, clinicians may find it difficult to raise such sensitive issues, adding a second block to the provision of anticipatory care [17]. Some suggested questions which may help open up a discussion about end-of-life needs are listed in Box 2 . Beginning discussion early in the disease course, being open to opportunities to discuss prognosis, and using the uncertain trajectory to ease discussion, are amongst the strategies identified by general practitioners as having 'worked' for them [18].

Box 2: Useful questions to open a discussion about end-of-life needs

- If things got worse, where would you like to be cared for?

- What's the most important issue in your life right now?

- What helps you keep going?

- What is your greatest problem?

- You seem cheerful at present, but do you ever feel down? 


\section{What can we do for patients with COPD on the register?}

Despite the paucity of specific evidence in people with end-stage COPD, there are general principles of palliative care which are likely to be applicable. As well as wanting information and control of symptoms, patients with progressive illnesses appreciate continuity of care and proactive management [19]. Personal continuity by a named doctor or nurse is ideal, and continuity of information within the primary care team (including out-of-hours services) should be ensured. The Gold Standards Framework [20], which highlights seven key tasks in providing co-ordinated care, has been widely adopted for people with advanced cancer. Although some innovative practices report using this framework for people with organ failure, research is needed to assess the applicability of this and other models of care for people with end-stage COPD.

We 'do death badly' for people with COPD. In the UK, the targets set by the General Medical Services contract offer an opportunity to improve care for people with severe COPD and their carers. If we can accept the challenge of identifying COPD patients approaching the end of life, we should be better able to help them plan for a good death: a death where they wish, with the peop!o tin $=y$ Want, and with minimal physicat ps.cchological and spiritual distress.
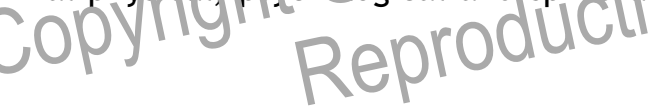

\section{Conflicts of interest}

There are no conflicts of interest to declare.

\section{References}

[1] Lunney JR, Lynn J, Foley DS, Lipson S, Guralnik JM. Patterns of functional decline at the end of life. JAMA 2003;289:2387-92.

[2] World Health Organisation. Palliative Care: The Solid Facts. World Health Organisation, 2004.

[3] NHS Confederation, British Medical Association. Revisions to the GMS contract 2006/7: delivering investment in general practice. London, 2006. Available from http:// www.bma.org.uk/ap.nsf/Content/revisionnGMSFeb20062.
[4] Murray SA, Boyd K, Sheikh A. Palliative care in chronic illness. We need to move from prognostic paralysis to active total care. BMJ 2005;330:611-2.

[5] Skilbeck J, Mott L, Page H, Smith D, Hjelmeland-Ahmedzi $S$, Clark D. Palliative care in COPD: a needs assessment. Palliative Med 1998;12:245-54.

[6] Lynn J, Ely EW, Zhong Z, McNiff KL, Dawson NV, Connors A, et al. Living and dying with chronic obstructive pulmonary disease. J Am Geriatrics Soc 2000;48:S91-S100.

[7] Elkington $\mathrm{H}$, White $\mathrm{P}$, Addington-Hall J, Higgs R, Pettinari C. The last year of life of COPD: a qualitative study of symptoms and services. Respir Med 2004;98:439-45.

[8] Elkington $\mathrm{H}$, White P, Addington-Hall J, Higgs R, Edmonds $P$. The healthcare needs of chronic obstructive pulmonary disease patients in the last year of life. Palliative Medicine 2005;19:485-91.

[9] Gore JM, Brophy CJ, Greenstone MA. How well do we care for patients with end stage chronic obstructive pulmonary disease (COPD)? A comparison of palliative care and quality of life in COPD and lung cancer. Thorax 2000;55:1000-6.

[10] Grant E, Murray SA, Kendall M, Boyd K, Tilley S, Ryan D. Spiritual issues and needs: perspectives from patients with advanced cancer and non-malignant disease: a qualitative study. Pall Supp Care 2004;2:371-8.

[11] House of Commons Health Committee. Palliative care. London: The Stationery Office; 2004.

[12] World Health Organisation. 2006. Definition of Palliative Care. Available from: http://www.who.int/cancer/ palliative/definition/en/.

[13] Lynn J, Adamson DM. Living we Il ct che end of 'ife. Adapting health care to sericus clionic ille ess in old age. 2003 RAND Santa Morica.

[17] Ch istak is NA, Lamont EB. Extent and determinants of error in doctor's pros nosis $m$ terminally ill patients: prospective conort S icy. L îL 2000;320:469-72.

[151 A nasro P, Calbo E, de Echagüen AO, Quintana BBS, Heredia JL, Garau J. Mortality After Hospitalization for COPD. Chest 2002;121:1441-8.

[16] Connors AF, Dawson NV, Thomas C, Harrell F, Desbiens $\mathrm{N}$, Fulkerson WJ, et al. Outcomes following acute exacerbation of chronic obstructive lung disease. The SUPPORT investigators. Am J Respir Crit Care Med 1996;154:959-67.

[17] Mulcahy P, Buetow S, Osman L, Coster G, Bray Y, White P, et al. GPs attitudes to discussing prognosis in severe COPD: an Auckland (NZ) to London (UK) comparison. Family Practice 2005;22:538-40.

[18] Halliwell J, Mulcahy P, Buetow S, Bray Y, Coster G, Osman L. GP discusson of prognosis with patients with severe chronic obstructive pulmonary disease: a qualitative study. $\mathrm{Br} \mathrm{J}$ Gen Pract 2004;54:904-8.

[19] Murray SA, Kendall M, Boyd K, Sheikh A. Illness trajectories and palliative care. Clinical Review. BMJ 2005;330:1007-11.

[20] NHS End-of-Life Care programme. The Gold Standards Framework. A programme for community palliative care. Available from http: / / www.goldstandardsframework. nhs.uk.

Available online at www.sciencedirect.com ScienceDirect 